\title{
Practise Mining to Predict Type of Client Performence
}

\author{
C. Nalini, R.Kavitha, G.Kavitha, S.Sangeetha
}

\begin{abstract}
The aim of process mining implement is firstly to discover the typical customer fulfillment business process-process mining act as a bridge between data mining and web mining. Process mining in an active innovative research area in recent year. The goal is to be extract process -related information from the event log by observing events recorded by some of the information system using the click stream method. Finally we are classifying the different categories of customer behavior using weka tool after we applied the knowledge miner. The result provides to find the different type of customer and their behavior and its helps the company to improve the product and satisfied customer needs.
\end{abstract}

KEYWORDS:Data mining, Nä̈ve bayes, IBK, J48

\section{INTRODUCTION}

Web mining is applying a data mining method in the World Wide Web mining method and discovering pattern. Web mining is split into three different classifications[1][2]. Web mining is a branch of an data mining in an concentrating on the world wide in an web as the primary data source including all the web content and server logs.

Web content mining in this process mining can useful information from the contents of web page and web document .web content mining can be used in a mining of useful data information knowledge from the web page content mining[3][4]. Web content performs scanning and the text mining images and groups in a web page according to content in an input display in an search engine. In this process web structure mining tries to an discover useful knowledge from the structure of the hyperlink.

Web use mining in this phase of extracting patterns and data in server records to obtain insight into customer behavior including where the customers are how many touched and the object on the page and the sort of operation being performed on a page[5][6]. Web usage mining focuses specifically on discovering trends related to web-based system customers and may specifically focus on discovering

Revised Manuscript Received on July 22, 2019.

C.Nalini, Department of computer science engineering, Bharath Institute of Higher Education and Research ,Chennai, Thamilnadu ,India.

R. Kavitha, Department of CSE, Bharath Institute of Higher Education and Research, Chennai, Tamilnadu, India.

G. Kavitha, Assistant Professor, Department of Computer Science and Engineering, Bharath Institute of Higher Education and Research, Chennai, India.

S. Sangeetha, Department ofCSE, Bharath Institute of Higher Education and Research, Chennai, Tamilnadu, India. trends related to web mining customers. Web usage mining depends on information recorded in the background.

Web crawler is a program or automated script which browser the World Wide Web in a methodical, automated manner internet boot which helps to a web indexing[7][8]. In this crawl using one page at a time through the web site until the entire page has been indexing. Web crawlers help in a collecting the information about a web site and the link related to them, and also help in validating the html code and hyper links.

A click stream is a file that includes information about using a mouse or touchpad to click a website user on a computer display screen. This sort of data in gives thorough reviews on a visual path of customer behavior. Such information and associated assessment promote real-time customer activity market research and other scenarios. The concept behind click stream is that study can learn a lot from how and where consumers click on a blog about customer interaction and psychology.

The process mining is one of the techniques in the field of process management. In this technique to support the analysis of business process based in an event logs. The process mining in a recent research discipline which is used to the discover knowledge from the event logs and the process can be extracted from the available information system like to transaction log file from a normal database table. The process mining is a suitable for application in any industry and process[9][10]. In this company have a several factories in different region and they can usually are difference between the reliability of deliveries. In this data can be achieved by visualizing the data in process context the flow charts and creating analyzes that give information to needed improvement depend understanding what is going on the business process.

\section{LITERATURE SURVEY}

K.Maheswari ,p.packia amutha priya 2017 : In paper using SVM classifier technique compare naïve bayes. Finally in this paper using the classification algorithm with SVM technique .The customer who has are less than 7 was attracted more in buy on line product in recent year. so they analyzed with other classification of future work[11].

Shalini Gupta, Uma Ojha and Veer Sain Dixit 2017: In this research using RSS strong feature to provide the accurate better prediction and

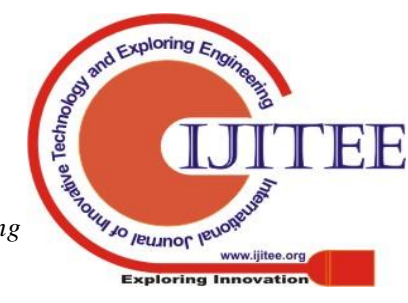


recommendation of item. In this previous paper RS basic user navigational behavioral pattern further in this study apply ARM cluster and extend work analyzing the sequential pattern applying CF refining data. Finally they analyze the pattern can be combine to RS order and enhance to performance and efficiency[12].

Farshad Kooti 2016 :In this paper they are using demographic factor use our performs the baselines and especially to predict the price of an next purchase first they can only capture purchase for confirmation email has been delivered .similarly the people can share the purchasing amount to enjoy the some benefits. In previous paper they consider such data extracted from email and combined with consumer demographic information which we use to characteristics model and predict the purchasing behavior we analyze behavior of customer in different age and gender group and find interesting actionable pattern to improve the system.

\section{SERGIO HERNÁNDEZ 2017:}

This result are using LTL model using text mining the different queries are identify different customer behavior are performed in an user during the session. In this strategy, adding it to actual case research on the trade page was a true research. This outcome identifies the possibility of proposing some enhancement in the layout of the website with the objective of growing effectiveness. In previous paper there are different predefined queries can be performed to an identify behavior pattern in different action on during a user session.

\section{GÖKHAN SØLAHTAROÖLU 2017 :}

In this research using KNIME algorithm in WEKA tool they applied the artificial neural network in OLAP and compare the confusion matrix and over all accuracy. In this paper they identified the first part of an studying, data about the customer house movement (what and what they click) and they are using demographic information (age, sex, neighborhood) and item they added to the shopping basket have been collected .In previous paper works as click stream or the module movement of e- customer to make provide some hints about buying behavior.

\section{METHODOLOGY}

\section{A Dataset:}

Online shopping data set:

A data set is downloaded from data.world.com. the list involve 1,4596 online review type of products from websites like A trapalo's and best buy provide by a online shopping database. The dataset include 5 attribute like view, compare, transaction, add to card, logout etc. In this project using click stream data to identify the different type of customer to classify the customer type.

\section{B. Data preprocessing:}

Web log files are not formatted to be mined and cannot be directly used if one hopes to create a solid model. Raw web logs have to go through different stages in order to become mine-able. For instance, the original $\operatorname{logs}$ contain several records of user requests for web scripts or images. Web site that is not relevant to click stream mining. To applied the filter preprocessing technique. To classify the three types of behaveior.

\section{THREE TYPES OF BEHAVIOR}

- There are different types of characteristics to purchase the item. In this type, it has divided three categories. For that first classify the three types of categories using with weka tool.

- Bargain shopper using information about campus discount in online store the Bargain shopper searching and Purchasing along deals with the strength of extreme reason.

- Surgical shopper knows precisely what they want before registering online and only buy that item they usually understand the requirements on which to base their choice, find data to suit the requirements and buy when they are sure they have discovered precisely the correct product.

- Power shopper is typically people who " shop around" and know where to find the best deals. The customer to look for the best price, ensure they are making the best decision, and then make a purchase.

To find the three type of customer behavior using the $\mathrm{k}$ means algorithm in cluster techniques.

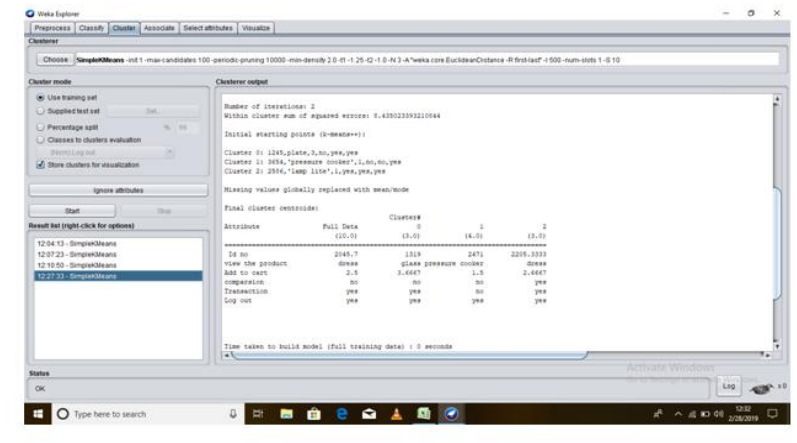

\section{VII.CASE 1-BARGAIN SHOPPER}

In bargain shopper to start the view of product and compare, add to cart transaction and then log

\section{C..Case Bargain Shopper}

In bargain shopper to start the view of product and compare, add to cart transaction and then $\log$

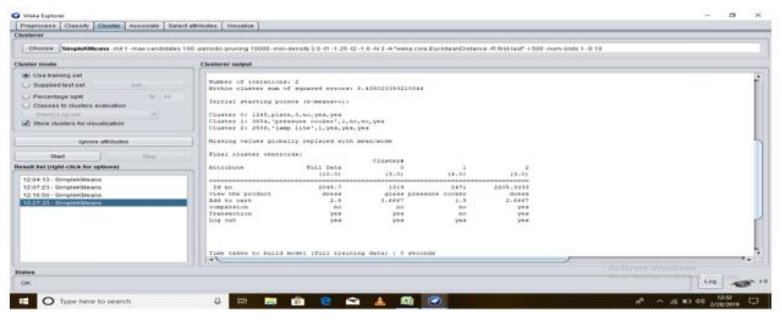




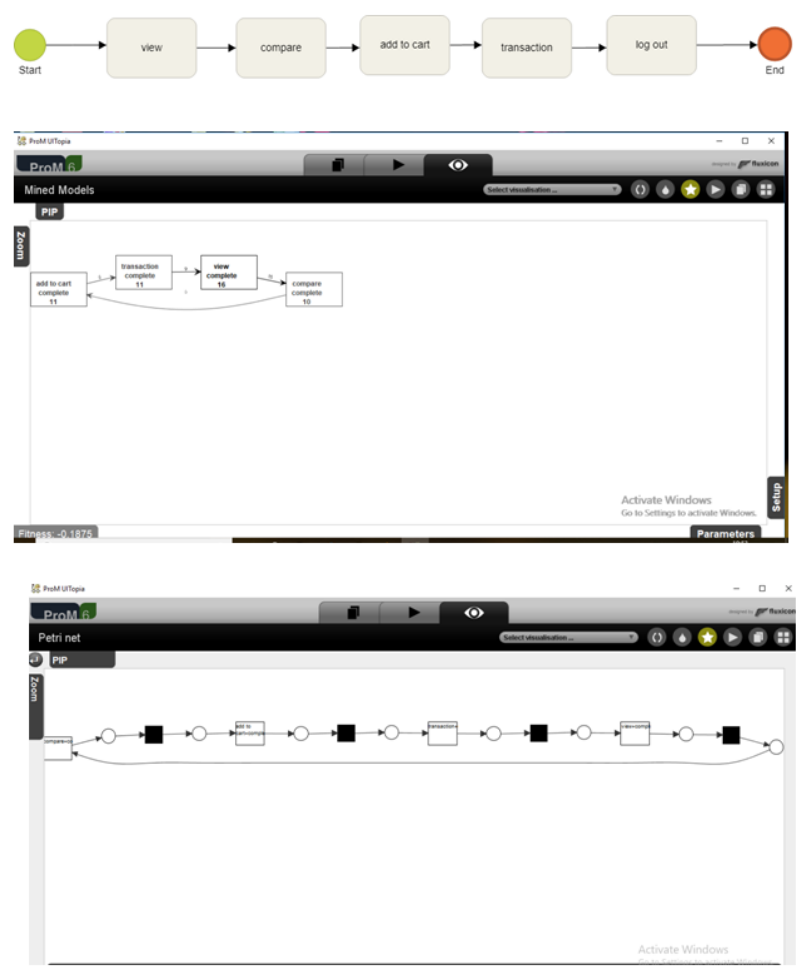

\section{C.Case 2}

In case 2 surgical shopper we have to start the view of product and add to cart , transaction and logout the account in second case.

Highlight a section that you want to designate with a certain style, and then

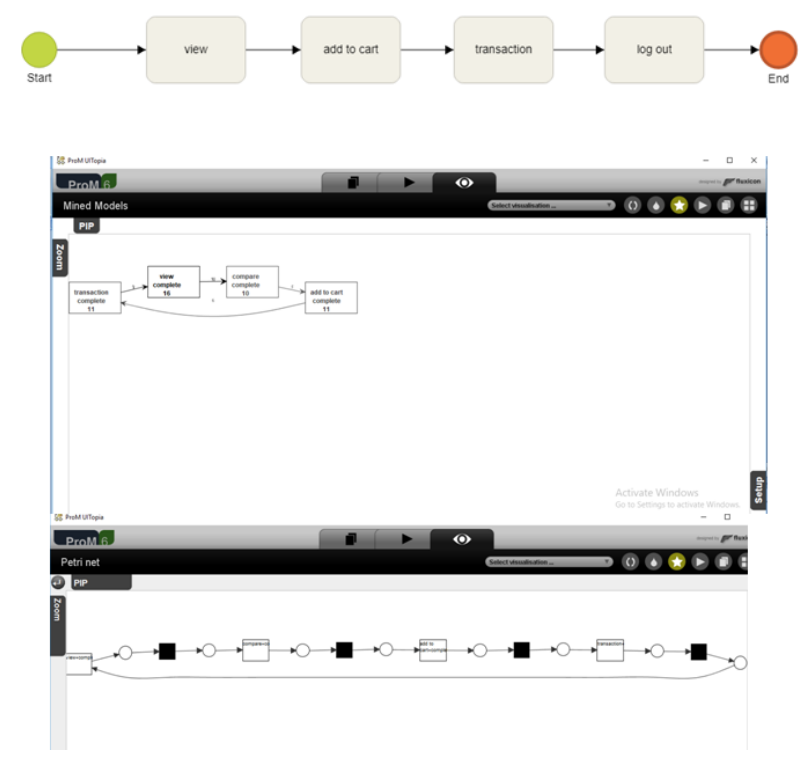

\section{D.Case 3}

In case 3 power shopper we have to start the view of product and compare, add to cart then we have to logout the account in third case.

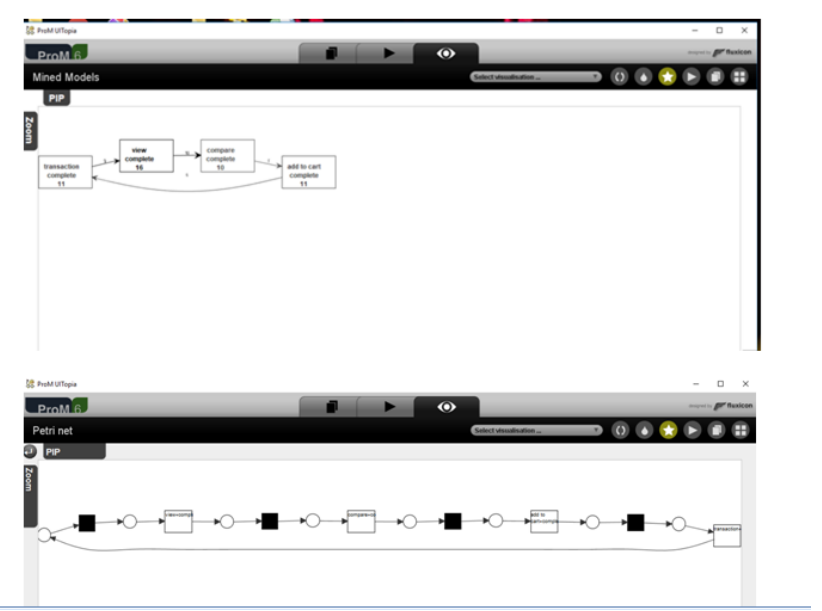

Classification is a process of predefine class. Classification process and predict the model in a continuous valued function. The major issues is preparing the data and classification

- Classification model is and find predict the class and labels.

- The steps are classifying the algorithm and build the classifier.

- The classifier is built from a training set and made a data tuples associate the class labels.

\section{E.Naïve Bayes}

A Naive Bayes is an algorithm which can be used to categorized items using a bayes theorem. Naive bayes classifier implies that the attribute of information points is powerful and dependent. A naive bayes classifier's popular uses include the spam filter. A naive bayes classifier utilizes the concept of probability to rank an algorithm using a theorem of bayes. A naive bayes classifier is not a single algorithm in machine learning.

\section{F. K- nearest neighbour:}

This algorithm is simplest for all machine learning algorithms. A k nearest neighbour is a data classification in an algorithm attempt to learn the determine what group a data point around it. A k nearest neighbour algorithm is an approach to identify the data classification the estimate can be likely data point to be members or one group depending the data point are nearest.

\section{G. J48}

Decision tree $\mathrm{j} 48$ is a implemented algorithm in an develop the data set and how to predict the data and target variable of new data set recordA decision tree is a decision support system that utilizes a tree as a graph choice to make it feasible to alter an occurrence lead after the efficient includes. A supervised classification is considered to check a issue because of the autonomous variable and the number of courses.

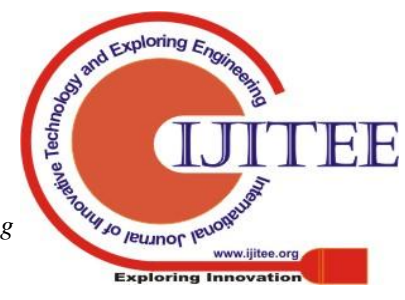




\begin{tabular}{|l|l|l|l|l|l|}
\hline ALGORITHM & Accuracy & TP Rate & $\begin{array}{l}\text { F-measure } \\
\text { precision }\end{array}$ & Precision & Recall \\
\hline Decision tree & 98 & 0.955 & 0.977 & 1.000 & 0.954 \\
\hline Naive baves & 92 & 0.750 & 0.818 & 0.900 & 0.750 \\
\hline IBK & 98 & 0.980 & 0.980 & 0.982 & 0.980 \\
\hline
\end{tabular}
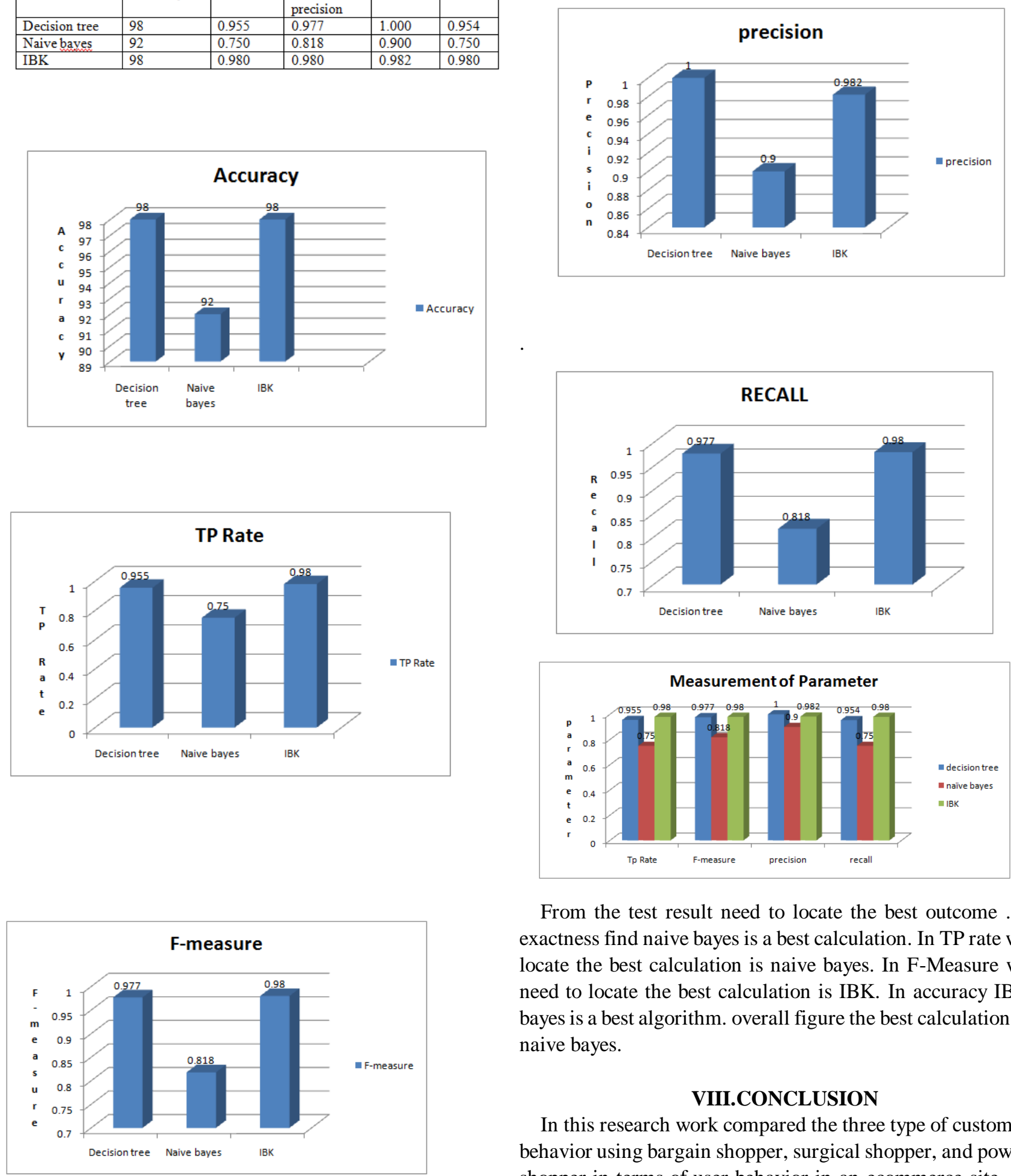

From the test result need to locate the best outcome .In exactness find naive bayes is a best calculation. In TP rate we locate the best calculation is naive bayes. In F-Measure we need to locate the best calculation is IBK. In accuracy IBK bayes is a best algorithm. overall figure the best calculation is naive bayes.

\section{VIII.CONCLUSION}

In this research work compared the three type of customer behavior using bargain shopper, surgical shopper, and power shopper in terms of user behavior in an ecommerce site. In this result are classify the dataset using various technique to find the different parameter and find the best classification method implemented in weka tool and to find the different type of customer and predict their behavior in click stream data. Finally we find the different type of customer behavior.

\section{REFERENCES}

[1] Liu Hongyan and Liu Zhenyu(2015): E-Commerce Consumer Behavior Information Big Data Mining nternational Journal of Database Theory and

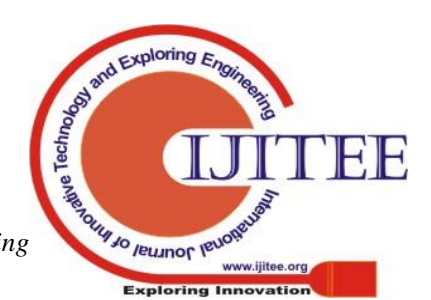


Application Vol.9, No.7 (2016), pp.135-146

Bhumika Pahwa, Dr. S. Taruna, Dr. Neeti Kasliwal(2017): Role of Data mining in analyzing consumer's online buying behavior. International Journal of Business and Management Invention ISSN (Online): 2319 - 8028, November. 2017

[3] Irene S.Y. Kwan, Joseph Fong and H.K. Wong (2014):An e-Customer Behavior Model with Online Analytical Mining for Internet Marketing Planning.

[4] C.Nalini,Shwtambari Kharabe,"A Comparative Study On Different Techniques Used For Finger - Vein Authentication", International Journal Of Pure And Applied Mathematics, Volume 116 No. 8 2017, 327-333, Issn: 1314-3395

[5]. A.Sangeetha,C.Nalini,"Semantic Ranking based on keywords extractions in the web", International Journal of Engineering \& Technology, 7 (2.6) (2018) 290-292.

[6] JulijaPragarauskait e( 2012 ):E-Commerce Consumer Behavior Information Big Data Mining International Journal of Database Theory and Application Vol.9, No.7 (2016), pp.135-146.

[7] Kavitha, R., Nedunchelian, R., "Domain-specific Search engine optimization using healthcare ontology and a neural network backpropagation approach", 2017, Research Journal of Biotechnology, Special Issue 2:157-166

[8] Namrata Pawar ,monali gaikwad (2017): Analysis and prediction of E-customers behavior by mining clickstream data.international journal of advance research,idea innovation in technology ISSN:2454-132x

[9] Sergio Hernandez,pedro alvarez,Javier fabra,and Joaquin ezpeleta(2017) :Analysis of Users'Behavior in Structured e-Commerce Websites. Received April 3, 2017, accepted May 16, 2017, date of publication May 24, 2017, date of current version July 17, 2017.

[10] S.V.Gayathiri Devi,C.Nalini,N.Kumar,"An efficient software verification using multi-layered software verification tool "International Journal of Engineering \& Technology, 7(2.21)2018 454-457

[11] Donghyun Kim and Anthony P(2015): Ammeter Shifts in Online Consumer Behavior: A Preliminary Investigation of the Net Generation.journal of theoretical and applied electronic commerce research ISSn 0718-1876

[12] Gan Teck Wei, Shirly Kho, Wahidah Husain, Zurinahni Zaino(2015): A Study of Customer Behaviour Through Web Mining. Journal of Information Sciences and Computing Technologies feb-2015 ISSN 2394-9066

\section{AUTHORS PROFILE}

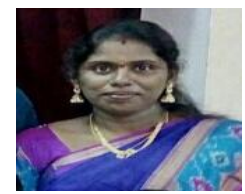

R. Kavitha, Associate Professor, Department of Computer Science and Engineering, Bharath Institute of Higher Education and Research, Chennai, India.

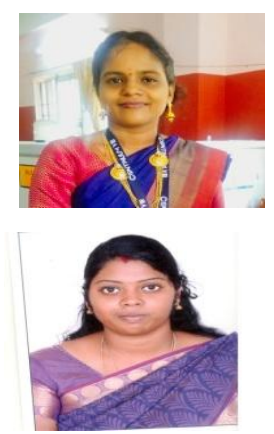

G. Kavitha, Assistant Professor, Department of Computer Science and Engineering, Bharath Institute of Higher Education and Research, Chennai, India.

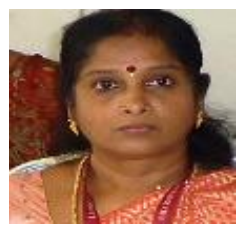

C.Nalini ,Department of computer science engineering, Bharath Institute of Higher Education and Research ,Chennai, Thamilnadu ,India
S. Sangeetha, Assistant Professor, Department of Computer Science and Engineering, Bharath Institute of Higher Education and Research, Chennai, India. 